\title{
SOME ASPECTS OF CHEMISTRY IN STRONGLY ACIDIC SOLVENT MEDIA
}

\author{
JOHN B. SENIOR \\ Department of Chemistry and Chemical Engineering, \\ University of Saskatchewan, Saskatoon, Saskatchewan, S7N OWO, Canada.
}

\begin{abstract}
An account is given of some recent developments in the chemistry of solutions in highly associated strong protonic acid solvents, including sulphuric acid and oleums, fluorosulphuric acid and hydrogen fluoride. Topics discussed include solvent-solute interactions, super-acid systems, Hammett acidity functions and polyatomic cations of the elements of Groups VI and VII.
\end{abstract}

\section{INTRODUCTION}

This paper reviews certain aspects of chemistry in the solvents sulphuric acid, disulphuric acid and oleums, fluorosulphuric acid, and anhydrous hydrogen fluoride.

\section{SOLVENT CHARACTERISTICS}

All of the solvents mentioned above have certain characteristics in common, which significantly affect their behaviour as solvents. They are all of course very strong protonic acids, or, otherwise expressed, electron-pair acceptors. Their most characteristic interaction with another molecule is the formation of a strong hydrogen bond, followed in most cases by transfer of a proton to the basic species (electron pair donor) involved:

$$
\begin{aligned}
& \text { B: }+\mathrm{H}-\mathrm{S}=\mathrm{B}:-\cdot-\mathrm{H}-\mathrm{S} \\
& \text { B: }-\cdots-\mathrm{H}-\mathrm{S}=\mathrm{B}-\mathrm{H}^{+}+: \mathrm{S}^{-}
\end{aligned}
$$

Despite their strong acid character, all of these solvents have in addition a by no means negligible basicity, arising from lone pairs of electrons on their oxygen atoms (or fluorine atom in the case of hydrogen fluoride). They can therefore accept hydrogen bonds from other molecules of the same kind, and are extensively associated in the liquid state. While details of the liquid structures are not known, it seems reasonable that units of the solid structures, chains, sheets or three-dimensional networks, persist as transient entities, constantly breaking down and reforming, in the liquid phase. As a consequence of their high degree of association, the acids have higher melting points and much higher boiling points than non-associated liquids of the same molecular weight, and wide and convenient liquid ranges. Their dielectric constants are relatively high, due to the cooperative orientation 
of the molecules in an electric field. This is in contrast to the behaviour of other strongly acidic solvents, such as the higher hydrogen halides, which are only very weakly basic, and are much less associated, more volatile, and have low dielectric constants.

Transfer of a proton along a hydrogen bond, from one neutral solvent molecule, HS, acting as an acid, to its neighbour, acting as a base, followed by separation of the resulting ions, leads to self-ionization, or autoprotolysis:

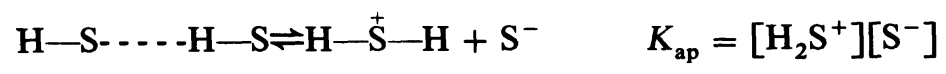

The autoprotolytic cation and anion are, respectively, the strongest acid and base that can exist as such in a given solvent. The extent of autoprotolysis, as measured by the magnitude of the autoprotolysis constant, $K_{\text {ap }}$ $=\left[\mathrm{H}_{2} \mathrm{~S}^{+}\right]\left[\mathrm{S}^{-}\right]$, clearly depends upon the base strength as well as the acid strength of the solvent molecules.

The autoprotolysis ions differ from solvent molecules only by the presence or absence of a proton, and can thus fit with minimum distortion into the solvent structure, being linked by hydrogen bonds to neighbouring solvent molecules. Proton transfers along hydrogen bonds occur very readily, permitting excess or defect proton sites to move rapidly through the solution without the necessity of the actual physical migration of ions. The application of an external electric field distorts the potential well in which the protons move in such a way as to favour proton transfers in the field direction, resulting in a net transfer of charge. This is shown diagrammatically below for the ion $\mathrm{S}^{-}$in the hypothetical solvent HS.

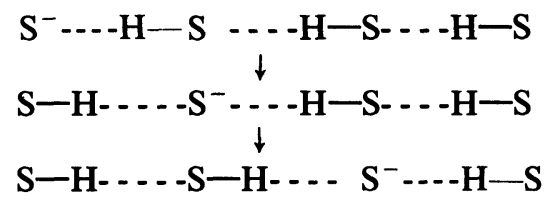

Only the autoprotolysis ions can conduct electricity by this proton transfer mechanism, in a given solvent, and these ions tend to have much higher mobilities than all other ions, which can conduct only by migration through the solution. In some cases, when the solvent is very viscous, the mobilities of normally conducting ions are very low, and the autoprotolysis ions conduct almost all of the current.

Recently, Zundel and co-workers ${ }^{1}$ have suggested that proton transfer conduction in aqueous solutions is associated with the presence of the species $\mathrm{H}_{5} \mathrm{O}_{2}{ }^{+}$and $\mathrm{H}_{3} \mathrm{O}_{2}{ }^{-}$in acidic and basic solutions, respectively. These species have the structures I and II, in which the bridging proton moves in a double potential well with a low energy barrier or in a very broad single minimum potential well.

$$
\mathrm{H}_{2} \mathrm{O}-\cdots-\mathrm{H}-\cdots-\mathrm{OH}_{2}^{+}
$$$$
\text { HO- - - - H- - - - } \mathrm{OH}^{-}
$$

Such hydrogen bonds are highly polarizable and give rise to infra-red absorption continua: The participation of analogous entities in proton 
transfer conduction in the strong acid solvents with which we are concerned seems highly plausible.

The completion of a proton transfer step leaves the solvent molecule in an unsuitable orientation to participate in a further transfer in the same direction. There are thus two possible rate-determining steps for this conduction mechanism: (1) proton transfer along a hydrogen bond, and (2) reorientation of a solvent molecule following proton transfer. Conway ${ }^{2}$ argued very convincingly some years ago, on the basis of deuterium isotope effects on ion mobilities, that in aqueous solutions the reorientation step is rate-determining. It has been argued that a molecular reorientation process is rate-determining in sulphuric acid also $^{3}$, and this would be expected to be the case in other strong acid solvents.

A related mechanism of conduction, the asymmetric autoprotolysis mechanism, was proposed by Wyatt $^{4}$. In the absence of an external electric field, proton transfers between pairs of neutral solvent molecules leading to self-ionization (equation 3) occur with equal frequency in all directions. Application of an external electric field causes a slight preponderance of such proton transfers to occur in the field direction. Since proton transfer in the reverse sense, i.e. from cation to anion to re-form two neutral molecules, occurs whenever a pair of ions approaches within a certain critical distance, under diffusion control, there is no preferred direction for this process, and the asymmetry of the ionization process results in a net transfer of charge. The contribution of this mechanism to the specific conductivity was shown to be directly proportional to the autoprotolysis constant of the solvent, $K_{\text {ap }}=\left[\mathrm{H}_{2} \mathrm{~S}^{+}\right]\left[\mathrm{S}^{-}\right]$. Thus the mechanism will only be important for extensively dissociated solvents. There is evidence that this mechanism makes a constant contribution to the conductivity of solutions in sulphuric acid equal to about 36 per cent of the conductivity of the pure solvent. It appears from the magnitude of their specific conductivities that both selenic ${ }^{5}$ and phosphoric ${ }^{6}$ acids are even more extensively dissociated than sulphuric acid, and it is to be expected that the asymmetric autoprotolysis mechanism of conduction will play a significant role in these two solvents also.

\section{SOLVENT-SOLUTE INTERACTIONS}

The importance of specific solvent-solute interactions, i.e. electron pair donor-acceptor interactions, in determining solute behaviour in a given solvent has been strongly emphasized in recent years, most notably, and from somewhat different points of view, by Drago ${ }^{7}$ and by Gutmann ${ }^{8,9}$. It has been shown that the ionization (as opposed to dissociation) of a covalent solute is determined relatively little by the dielectric constant of the solvent, but rather by the ability of the solvent to stabilize the ionic fragments formed, by the formation of coordinate covalent bonds. Thus for example the ionization of a covalent metal halide $\mathbf{M X}$ depends critically upon the ability of a solvent molecule to coordinate to the metal ion and so to displace a halide ion $\mathrm{X}^{-}$from its inner coordination sphere. The tendency towards ionization will be further enhanced if either the solvent molecule or some other molecule present is capable of behaving as an electron pair acceptor towards the displaced anion: 


$$
\mathrm{D}:-\mathrm{M}-\mathrm{X}:-\mathrm{A} \rightleftharpoons \mathrm{D}-\mathrm{M}^{+}, \mathrm{X}-\mathrm{A}^{-} \rightleftharpoons \mathrm{D}-\mathrm{M}^{+}+\mathrm{X}-\mathrm{A}^{-}
$$

Here D and A represent, respectively, electron pair donor and acceptor functions, which may both belong to the same kind of molecule, e.g. a solvent molecule, or to different molecules. Dissociation of the initial ionized species shown into free ions will occur to an extent determined mainly by the dielectric constant of the solvent.

The coordination approach has been most successfully applied to solution chemistry in electron pair donor solvents, in which cation stabilization through coordination by solvent molecules is of prime importance. It has been relatively little used in the discussion of chemistry in strong protonic acid solvents.

The reason for this is perhaps not far to seek. Although not devoid of basic properties, as has already been mentioned, these solvents are nonetheless, by normal standards, very weak bases. Cation solvation in these solvents will therefore tend to be of a non-specific nature, based primarily on ion-dipole interactions, with very little transfer of electron density from the solvent molecules to the cation. Probably because of the poor coordinating ability of the solvent molecules, most transition metal salts are of low solubility in strong acid solvents and relatively little transition metal chemistry has been studied in such media. It is in fact just because they are such poor electron pair donors that these solvents are so useful as media for the preparation of highly electrophilic cations, such as carbonium ions $\mathrm{R}_{3} \mathrm{C}^{+}$, $\mathrm{NO}_{2}^{+}$and polyatomic cations of the non-metallic elements, e.g. $\mathrm{I}_{3}^{+}, \mathrm{S}_{16}^{2+}$ and $\mathrm{Se}_{8}^{2+}$, which could not exist in more basic media.

I do not mean to imply that cation solvation is unimportant in strong acid solvents; only that it does not involve significant electron transfer to the cation. Reasonable solvation numbers have been obtained, for example, for a number of cations in sulphuric acid, based on osmotic coefficients derived from very accurate freezing point depression data ${ }^{10}$, and from apparent molar volumes ${ }^{11}$ (Table 1). It should be noted that the numbers cited are for

Table 1. Cation solvation numbers in sulphuric acid solutions of hydrogensulphates

\begin{tabular}{lllllllll}
\hline \multicolumn{1}{c}{ Cation } & $\mathrm{Li}$ & $\mathrm{Na}$ & $\mathrm{K}$ & $\mathrm{Rb}$ & $\mathrm{Cs}$ & $\mathrm{Ca}$ & $\mathrm{Sr}$ & $\mathrm{Ba}$ \\
\hline $\begin{array}{l}\text { Solvation number } \\
\text { from cryoscopy }\end{array}$ & 2.3 & 3.0 & 2.1 & - & - & - & - & 6.5 \\
$\begin{array}{l}\text { Solvation number } \\
\text { from molar volume }\end{array}$ & 2 & 3 & 2 & 1 & 0 & 8 & 8 & 5 \\
\hline
\end{tabular}

the solute $\mathrm{MHSO}_{4}$ or $\mathrm{M}\left(\mathrm{HSO}_{4}\right)_{2}$, and were assigned as cation solvation numbers on the basis of the assumption, now recognized to be incorrect, that the $\mathrm{HSO}_{4}^{-}$ion is not solvated. Furthermore the order of increasing specific conductivities of alkali metal hydrogensulphates in sulphuric acid at higher concentrations, $\mathrm{Li}<\mathrm{Na}<\mathrm{K}<\mathrm{Rb}<\mathrm{Cs}$, is most satisfactorily explained by assuming that the smaller ions are most strongly solvated, and thus by hindering the reorientation of solvent molecules, interfere most with proton transfer conduction by the $\mathrm{HSO}_{4}^{-}$anion ${ }^{3 \mathrm{~b}}$. Similar results in other strong 
acid solvents (e.g. $\mathrm{HSO}_{3} \mathrm{~F}^{12}, \mathrm{HSO}_{3} \mathrm{Cl}^{13}$ ) have been explained in the same way.

In contrast to their relatively weak interactions with cations, strong acid solvents interact strongly, by hydrogen bond formation, possibly followed by proton transfer, with even very weakly basic solutes. Soluble non-electrolytes are substances such as poly-nitrocompounds and sulphuryl halides, which although too feebly basic to undergo protonation, are basic enough to act as hydrogen bond acceptors toward the solvent, and so compensate for the breaking of hydrogen bonds between solvent molecules caused by the dissolution of the solute.

Anions of course interact very strongly with the solvent, and are usually completely solvolysed to their parent acids, which may then undergo some further reaction. Some examples, all for sulphuric acid as solvent, are given below:

$$
\begin{aligned}
& \mathrm{Cl}^{-} \stackrel{\mathrm{H}_{2} \mathrm{SO}_{4}}{\longrightarrow} \mathrm{HCl} \stackrel{\mathrm{H}_{2}}{\mathrm{SO}_{4}} \longrightarrow \mathrm{HSO}_{3} \mathrm{Cl}+\mathrm{H}_{3} \mathrm{O}^{+} \\
& \mathrm{NO}_{3}^{-} \stackrel{\mathrm{H}_{2} \mathrm{SO}_{4}}{\longrightarrow} \mathrm{HNO}_{3} \stackrel{\mathrm{H}_{2} \mathrm{SO}_{4}}{\longrightarrow} \mathrm{NO}_{2}^{+}+\mathrm{H}_{3} \mathrm{O}^{+} \\
& \mathrm{H}_{2} \mathrm{PO}_{4}^{-} \stackrel{\mathrm{H}_{2} \mathrm{SO}_{4}}{\longrightarrow} \mathrm{H}_{3} \mathrm{PO}_{4} \stackrel{\mathrm{H}_{2} \mathrm{SO}_{4}}{\longrightarrow} \mathrm{H}_{4} \mathrm{PO}_{4}^{+} \\
& \quad \mathrm{SO}_{3} \mathrm{~F}^{-} \stackrel{\mathrm{H}_{2} \mathrm{SO}_{4}}{\longrightarrow} \mathrm{HSO}_{3} \mathrm{~F}
\end{aligned}
$$

Interaction of the solvent with the anionic species released plays an important role in the ionization of certain covalent species in strong acid solvents, e.g.:

$$
\begin{aligned}
\left(\mathrm{CH}_{3}\right)_{3} \mathrm{C}_{6} \mathrm{H}_{2} \mathrm{COCl}+3 \mathrm{H}_{2} \mathrm{SO}_{4}=\left(\mathrm{CH}_{3}\right)_{3} \mathrm{C}_{6} \mathrm{H}_{2} \mathrm{CO}^{+}+\mathrm{HSO}_{3} \mathrm{Cl} \\
+\mathrm{H}_{3} \mathrm{O}^{+}+2 \mathrm{HSO}_{4}^{-} \\
\mathrm{ICl}_{3}+3 \mathrm{H}_{2} \mathrm{~S}_{2} \mathrm{O}_{7}=\mathrm{ICl}_{2}^{+}+\mathrm{HSO}_{3} \mathrm{Cl}+2 \mathrm{H}_{2} \mathrm{SO}_{4}+\mathrm{HS}_{3} \mathrm{O}_{10}^{-}
\end{aligned}
$$

The many instances in which cationic species are formed from hydroxycompounds may, at least formally, be regarded as examples of the abstraction of a hydroxide ion in the same way, e.g.:

$$
\mathrm{NO}_{2}(\mathrm{OH})+2 \mathrm{H}_{2} \mathrm{SO}_{4}=\mathrm{NO}_{2}^{+}+\mathrm{H}_{3} \mathrm{O}^{+}+2 \mathrm{HSO}_{4}^{-}
$$

Many of the highly electrophilic cations which have been studied in strong acid solvents are in practice generated in solution, not by the ionization of pre-existing covalent compounds, but by the oxidation of the element concerned to the appropriate formal oxidation state in the acid medium. In these cases, too, the ability of the solvent to solvate or solvolyse anions is of importance for the stability of the cations in solution. Decomposition of the cation involves reaction with a base, usually an anion or water, to form a covalent species, often accompanied by disproportionation. Thus in fluorosulphuric acid the cation $\mathrm{Br}_{2}^{+}$reacts with fluorosulphate ion, with disproportionation: ${ }^{14}$

$$
2 \mathrm{Br}_{2}^{+}+\mathrm{SO}_{3} \mathrm{~F}^{-} \rightleftharpoons \mathrm{Br}_{3}^{+}+\mathrm{BrSO}_{3} \mathrm{~F}
$$

Anions which are stronger bases than the solvent anion are of course fully solvolysed and are thus prevented from reacting with the electrophilic species. The basicity of the solvent anion itself is also reduced by solvation, as its charge is partly delocalized onto the solvent molecules to which it is 
hydrogen bonded. We may think of a reaction such as the above as involving competition between two acids, namely the electrophile, e.g. $\mathrm{Br}_{2}^{+}$, and the bulk solvent, for the strongest available base, the solvent anion:

$$
2 \mathrm{Br}_{2}^{+}+\mathrm{SO}_{3} \mathrm{~F}^{-} \cdot n \mathrm{HSO}_{3} \mathrm{~F} \rightleftharpoons \mathrm{Br}_{3}^{+}+\mathrm{BrSO}_{3} \mathrm{~F}+n \mathrm{HSO}_{3} \mathrm{~F}
$$

In this particular instance the bulk solvent is not a sufficiently strong acid to compete effectively, and the disproportionation is effectively complete in fluorosulphuric acid solution.

It was at one time believed that an anion such as $\mathrm{SO}_{3} \mathrm{~F}^{-}$or $\mathrm{HSO}_{4}^{-}$would not be solvated in its parent solvent, because of its large size. This assumption, based on a purely electrostatic view of solvation, is now recognized to be incorrect. In order to conduct by the proton transfer mechanism, the anion must of necessity form strong hydrogen bonds to neighbouring solvent molecules. Studies of ${ }^{1} \mathrm{H}$ chemical shifts in solutions of metal hydrogen sulphates in sulphuric acid showed that the average signal, for the rapidly exchanging $\mathrm{H}_{2} \mathrm{SO}_{4}$ and $\mathrm{HSO}_{4}^{-}$protons, was strongly shifted to lower field from that of the solvent alone ${ }^{15,16}$. Since the proton of an isolated $\mathrm{HSO}_{4}^{-}$ ion would be more shielded than those of $\mathrm{H}_{2} \mathrm{SO}_{4}$, a shift to higher field would have been anticipated, if the anion were indeed not solvated. The results could only be explained by assuming that the $\mathrm{HSO}_{4}^{-}$ion is strongly hydrogen bonded to solvent molecules, leading to deshielding of the protons. Similar results have recently been reported for solutions of fluorides in anhydrous hydrogen fluoride ${ }^{17}$, and perchlorates in anhydrous perchloric acid $^{18}$.

To summarize: whereas in donor solvents, cationic species are stabilized in solution by strong coordination to solvent molecules, the stability of highly electrophilic cations in strong acid media depends rather upon the absence of any strong specific interaction between solvent molecules and cations and upon the strong interaction of the solvent with basic species, such as anions, with which the cation might otherwise react.

\section{SUPER-ACID SYSTEMS}

As was stated above, the $\mathrm{Br}_{2}^{+}$cation is unstable towards disproportionation in fluorosulphuric acid, because the solvent is not a strong enough acid to compete effectively with the cation for the fluorosulphate anion. $\mathrm{The}^{\mathrm{B}} \mathrm{Br}_{2}^{+}$ cation can, however, be stabilized by the addition to the solution of the still stronger acid, $\mathrm{SbF}_{2}\left(\mathrm{SO}_{3} \mathrm{~F}\right)_{3}$, which combines with fluorosulphate ion to form the anion, $\mathrm{SbF}_{2}\left(\mathrm{SO}_{3} \mathrm{~F}\right)_{4}^{-}$, and so shifts the equilibrium in equation 12 to the left. Extremely acidic media, such as a solution of $\mathrm{SbF}_{2}\left(\mathrm{SO}_{3} \mathrm{~F}\right)_{3}$ in fluorosulphuric acid, can be used to protonate exceedingly weak bases, and to stabilize highly electrophilic cations, and are often referred to as superacids. This term has tended to be used rather loosely; perhaps the concept does not permit a very precise definition. A recent suggestion by Gillespie ${ }^{19}$ that the term 'super-acid' be used to refer to any medium which is more acidic than $100 \%$ sulphuric acid, seems to be finding favour among other workers in the field. This definition would include a number of pure solvents, such as fluorosulphuric, chlorosulphuric and trifluoromethanesulphonic 


\section{STRONGLY ACIDIC SOLVENT MEDIA}

acids, and probably anhydrous perchloric acid, as well as the systems containing complex acids which have usually been referred to by this term.

According to the Brønsted concept, an acid in a given solvent is a species which can donate a proton to a solvent molecule, to form the autoprotolysis cation of the solvent:

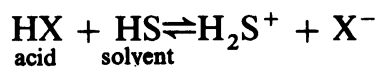

The formation of $\mathrm{H}_{2} \mathrm{~S}^{+}$will of course shift the autoprotolysis equilibrium so as to reduce the concentration of the solvent anion, $\mathrm{S}^{-}$.

The acid species may be a complex between a strong electron pair acceptor, $\mathrm{A},\left(\right.$ e.g. $\mathrm{SbF}_{2}\left(\mathrm{SO}_{3} \mathrm{~F}\right)_{3}$ in the above example) and a solvent molecule, in which the latter acts as a weak electron pair donor:

$$
\mathrm{HS}:+\mathrm{A}=\mathrm{HS}-\mathrm{A}
$$

Since the formation of such a complex involves a shift of electron density away from the proton site, the complex will be a stronger acid than HS itself:

$$
\mathrm{H}^{\delta+} \simeq \mathrm{S}:-\mathrm{A}^{\delta-}
$$

It will therefore ionize in solution in HS:

$$
\mathrm{HS}+\mathrm{HSA} \rightleftharpoons \mathrm{H}_{2} \mathrm{~S}^{+}+\mathrm{SA}^{-}
$$

In only a few cases is there definite evidence for the existence of the neutral complex acid HSA. Where such evidence is lacking it may be more correct to think of the un-ionized form of the acid as the electron pair acceptor A itself, which combines with a solvent anion:

$$
\mathrm{A}+\mathrm{S}^{-} \rightleftharpoons \mathrm{AS}^{-}
$$

Removal of $\mathrm{S}^{-}$then shifts the autoprotolysis equilibrium so that the concentration of $\mathrm{H}_{2} \mathrm{~S}^{+}$is increased.

Among the first super-acid systems to be studied were dilute oleums, solutions of excess sulphur trioxide in sulphuric acid. These solutions contain disulphuric acid, $\mathrm{H}_{2} \mathrm{~S}_{2} \mathrm{O}_{7}$, which may be regarded as a complex between the electron pair acceptor $\mathrm{SO}_{3}$ and a solvent molecule $\mathrm{H}_{2} \mathrm{SO}_{4}$. Disulphuric acid behaves as a weak acid in sulphuric acid:

$$
\begin{gathered}
\mathrm{H}_{2} \mathrm{SO}_{4}+\mathrm{SO}_{3}=\mathrm{H}_{2} \mathrm{~S}_{2} \mathrm{O}_{7} \\
\mathrm{H}_{2} \mathrm{~S}_{2} \mathrm{O}_{7}+\mathrm{H}_{2} \mathrm{SO}_{4} \rightleftharpoons \mathrm{H}_{3} \mathrm{SO}_{4}^{+}+\mathrm{HS}_{2} \mathrm{O}_{7}^{-}
\end{gathered}
$$

More concentrated oleums contain higher polysulphuric acids, $\mathrm{H}_{2} \mathrm{~S}_{3} \mathrm{O}_{10}$, $\mathrm{H}_{2} \mathrm{~S}_{4} \mathrm{O}_{13}$, etc., which are somewhat stronger acids than disulphuric acid. Oleum containing $50 \mathrm{~mole} \% \mathrm{SO}_{3}$, corresponding to the stoichiometric composition $\mathrm{H}_{2} \mathrm{~S}_{2} \mathrm{O}_{7}$, is very extensively self-dissociated ${ }^{20}$ :

$$
2 \mathrm{H}_{2} \mathrm{~S}_{2} \mathrm{O}_{7} \rightleftharpoons \mathrm{H}_{2} \mathrm{SO}_{4}+\mathrm{H}_{2} \mathrm{~S}_{3} \mathrm{O}_{10}
$$

and

$$
3 \mathrm{H}_{2} \mathrm{~S}_{2} \mathrm{O}_{7} \rightleftharpoons \mathrm{H}_{2} \mathrm{SO}_{4}+\mathrm{H}_{2} \mathrm{~S}_{4} \mathrm{O}_{13}
$$

Self-ionization in this system is best represented by:

$$
2 \mathrm{H}_{2} \mathrm{~S}_{2} \mathrm{O}_{7} \rightleftharpoons \mathrm{H}_{3} \mathrm{SO}_{4}^{+}+\mathrm{HS}_{3} \mathrm{O}_{10}^{-}
$$




\section{JOHN B. SENIOR}

Still more concentrated oleums contain appreciable concentrations of free sulphur trioxide, in addition to polysulphuric acids.

Solutions prepared by dissolving the correct stoichiometric amounts of boric acid and sulphur trioxide in sulphuric acid contain the ions of the rather strong acid, $\mathrm{HB}\left(\mathrm{HSO}_{4}\right)_{4}$, tetrahydrogensulphatoboric acid ${ }^{21}$ :

$$
\mathrm{B}(\mathrm{OH})_{3}+2 \mathrm{H}_{2} \mathrm{SO}_{4}+3 \mathrm{SO}_{3}=\mathrm{H}_{3} \mathrm{SO}_{4}^{+}+\mathrm{B}\left(\mathrm{HSO}_{4}\right)_{4}^{-}
$$

Attempts to isolate the parent acid $\mathrm{HB}\left(\mathrm{HSO}_{4}\right)_{4}$ or its salts from concentrated solutions have been unsuccessful. Elimination of sulphuric acid and sulphur trioxide occurs, and polymeric products are obtained.

A complex acid of similar stoichiometry, $\mathrm{HAs}\left(\mathrm{HSO}_{4}\right)_{4}$ is formed in the reaction:

$$
\mathrm{As}_{2} \mathrm{O}_{3}+5 \mathrm{H}_{2} \mathrm{SO}_{4}+3 \mathrm{SO}_{3}=2 \mathrm{HAs}\left(\mathrm{HSO}_{4}\right)_{4}
$$

This is, however, a much weaker acid ${ }^{22}$. Sulphuric acid solutions of lead and tin tetraacetates contain the diprotic acids $\mathrm{H}_{2} \mathrm{~Pb}\left(\mathrm{HSO}_{4}\right)_{6}$ and $\mathrm{H}_{2} \mathrm{Sn}\left(\mathrm{HSO}_{4}\right)_{6}$, respectively ${ }^{23}, 24$, along with their singly and doubly charged anions:

$$
\begin{gathered}
\mathrm{M}(\mathrm{OAc})_{4}+10 \mathrm{H}_{2} \mathrm{SO}_{4}=\mathrm{H}_{2} \mathrm{M}\left(\mathrm{HSO}_{4}\right)_{6}+4 \mathrm{AcOH}_{2}^{+}+4 \mathrm{HSO}_{4}^{-} \\
\mathrm{H}_{2} \mathrm{M}\left(\mathrm{HSO}_{4}\right)_{6}+\mathrm{HSO}_{4}^{-} \rightleftharpoons \mathrm{HM}^{-}\left(\mathrm{HSO}_{4}\right)_{6}^{-}+\mathrm{H}_{2} \mathrm{SO}_{4} \\
\mathrm{HM}\left(\mathrm{HSO}_{4}\right)_{6}^{-}+\mathrm{HSO}_{4}^{-} \rightleftharpoons \mathrm{M}\left(\mathrm{HSO}_{4}\right)_{6}^{2-}+\mathrm{H}_{2} \mathrm{SO}_{4} \quad(\mathrm{M}=\mathrm{Sn}, \mathrm{Pb})
\end{gathered}
$$

Super-acidic solutions of these acids have not been obtained, as they are formed in the above reactions in the presence of an excess of acetic acid, which behaves as a strong base in sulphuric acid.

The only simple acids of the sulphuric acid system are fluorosulphuric acid, chlorosulphuric acid and trifluoromethanesulphonic acid, all of which are very weak. Dissociation constants for acids in sulphuric acid are shown in Table 2.

Table 2. Dissociation constants of acids in sulphuric acid at $25^{\circ} \mathrm{C}$

\begin{tabular}{llc}
\hline \multicolumn{1}{c}{ Acid } & \multicolumn{1}{c}{$K_{\mathrm{a}}\left(\mathrm{mol} \mathrm{kg}^{-1}\right)$} & Reference \\
\hline $\mathrm{HB}\left(\mathrm{HSO}_{4}\right)_{4}$ & $2 \times 10^{-1}$ & 22 \\
$\mathrm{H}_{2} \mathrm{~S}_{2} \mathrm{O}_{7}$ & $1.4 \times 10^{-2}$ & 22 \\
$\mathrm{H}_{2} \mathrm{~Pb}\left(\mathrm{HSO}_{4}\right)_{6}$ & $1.2 \times 10^{-2}\left(K_{1}\right)$ & 24 \\
& $1.8 \times 10^{-3}\left(K_{2}\right)$ & \\
$\mathrm{HSO}_{3} \mathrm{~F}$ & $2.3 \times 10^{-3}$ & 22 \\
$\left.\mathrm{HAs} \mathrm{HSO}_{4}\right)_{4}$ & $1.5 \times 10^{-3}$ & 22 \\
$\mathrm{HSO}_{3} \mathrm{Cl}$ & $9 \times 10^{-4}$ & 22 \\
$\mathrm{CF}_{3} \mathrm{SO}_{3} \mathrm{H}$ & $8 \times 10^{-4}$ & 25 \\
$\mathrm{HClO}_{4}$ & very weak & 22 \\
\hline
\end{tabular}

No simple acids are known in the fluorosulphuric acid system. Solutions of sulphur trioxide in fluorosulphuric acid have been shown by Raman spectroscopy to contain fluorodisulphuric acid, $\mathrm{HS}_{2} \mathrm{O}_{6} \mathrm{~F}$, but this substance shows barely detectable acidic properties in this solvent ${ }^{26}$.

Antimony pentafluoride gives solutions in fluorosulphuric acid which are considerably more acidic than the pure solvent ${ }^{27}$. Conductivity data have been interpreted in terms of the formation of the weak acid, $\mathrm{H}\left[\mathrm{SbF}_{5}\left(\mathrm{SO}_{3} \mathrm{~F}\right)\right]$. 


\section{STRONGLY ACIDIC SOLVENT MEDIA}

At higher concentrations, however, the conductivity is higher than can be accounted for assuming only this single acid species, and it is necessary to postulate the formation of a dimeric anion, $\left(\mathrm{SbF}_{5}\right)_{2} \mathrm{SO}_{3} \mathrm{~F}^{-}$, which behaves as the anion of a strong acid. The situation at $25^{\circ} \mathrm{C}$ can be represented by the following equations:

$$
\begin{gathered}
\mathrm{SbF}_{5}+\mathrm{HSO}_{3} \mathrm{~F}=\mathrm{H}\left[\mathrm{SbF}_{5}\left(\mathrm{SO}_{3} \mathrm{~F}\right)\right] \\
\mathrm{H}\left[\mathrm{SbF}_{5}\left(\mathrm{SO}_{3} \mathrm{~F}\right)\right]+\mathrm{HSO}_{3} \mathrm{~F}_{2} \mathrm{H}_{2} \mathrm{SO}_{3} \mathrm{~F}^{+}+\mathrm{SbF}_{5}\left(\mathrm{SO}_{3} \mathrm{~F}\right)^{-} \\
2 \mathrm{H}\left[\mathrm{SbF}_{5}\left(\mathrm{SO}_{3} \mathrm{~F}\right)\right]^{K_{2}} \rightleftharpoons \mathrm{H}_{2} \mathrm{SO}_{3} \mathrm{~F}^{+}+\left(\mathrm{SbF}_{5}\right)_{2} \mathrm{SO}_{3} \mathrm{~F}^{-} \\
K_{1}=3.7 \times 10^{-3} \mathrm{~mol} \mathrm{~kg}^{-1} ; K_{2}=7 \times 10^{-3}
\end{gathered}
$$

${ }^{19} \mathrm{~F}$ n.m.r. studies led to the structure III, containing octahedrally coordinated antimony, for the monomeric acid. This is one instance where the existence of the neutral complex acid may be regarded as well-established. The monomeric anion differs from III only by the loss of the proton. The dimeric anion has the structure IV, also containing octahedral antimony, with a bridging fluorosulphate group.

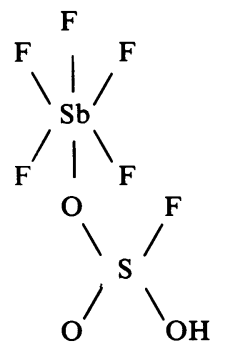

III

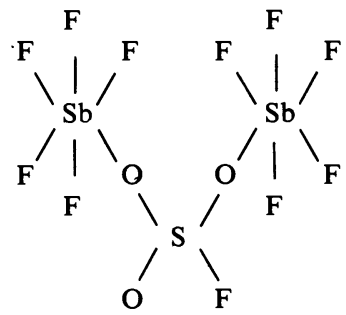

IV

The fluorosulphate group in the monomeric anion is more weakly basic than a free fluorosulphate ion, because it donates electron density to the $\mathrm{SbF}_{5}$ group, but still retains some basic character, as shown by its ability to coordinate to a proton, to form the un-ionized acid, or to a second $\mathrm{SbF}_{5}$ molecule, to form the dimeric anion. The bridging fluorosulphate group in the dimeric anion, coordinated to two strongly acidic $\mathrm{SbF}_{5}$ groups, retains almost no basic character. A similar situation has long been familiar in aqueous solutions of hydrogen fluoride, in which the polymers, $(\mathrm{HF})_{n}$, present at higher concentrations, are stronger acids than the monomer HF. In this case the basicity of the fluoride ion is reduced by coordination to one or "more HF molecules in the anions $\mathrm{H}_{n-1} \mathrm{~F}_{n}^{-}$.

Solutions of antimony pentafluoride in fluorosulphuric acid have found very wide use for the protonation of very weak bases, and for the preparation of unstable carbonium ions, especially in the work of Olah and his co-workers ${ }^{28}$. The name 'magic acid' has been given to the solution containing $50 \mathrm{~mol} \%$ $\mathrm{SbF}_{5}$.

The addition of sulphur trioxide to solutions of antimony pentafluoride in fluorosulphuric acid, up to the mole ratio $\mathrm{SO}_{3} / \mathrm{SbF}_{5}=3.0$, results in increased acid strength ${ }^{37}$. Sulphur trioxide is inserted into up to three $\mathrm{Sb}-\mathrm{F}$ bonds, resulting in the substitution of fluorosulphate for fluoride, with 
formation of the compounds $\mathrm{SbF}_{5-n}\left(\mathrm{SO}_{3} \mathrm{~F}\right)_{n}$, where $n=1,2$ or 3. Fluorosulphate ion is much less basic than fluoride, since its charge is more delocalized, so that the substituted compounds are more acidic than $\mathrm{SbF}_{5}$ itself. ${ }^{19} \mathrm{~F} \mathrm{n}$.m.r. studies have shown the presence of the acids $\mathrm{H}\left[\mathrm{SbF}_{5-n}\left(\mathrm{SO}_{3} \mathrm{~F}\right)_{n+1}\right]$ and/or their monomeric anions. Dimeric, fluorosulphate-bridged anions with structures analogous to IV are also believed to be present, although only for the ion $\left[\mathrm{SbF}_{4}\left(\mathrm{SO}_{3} \mathrm{~F}\right)\right]_{2} \mathrm{SO}_{3} \mathrm{~F}^{-}$could a separate n.m.r. spectrum be observed. The detailed interpretation of the conductimetric titration curve of $\mathrm{SbF}_{5} \cdot 3 \mathrm{SO}_{3}$ with the strong base, potassium fluorosulphate, was only possible on the assumption that both monomeric and dimeric anions were formed, and that both were anions of strong acids ${ }^{27}$. The situation in solutions of this solute can be summed up in the equations:

$$
\begin{gathered}
\mathrm{SbF}_{2}\left(\mathrm{SO}_{3} \mathrm{~F}\right)_{3}+2 \mathrm{HSO}_{3} \mathrm{~F}=\mathrm{H}_{2} \mathrm{SO}_{3} \mathrm{~F}^{+}+\mathrm{SbF}_{2}\left(\mathrm{SO}_{3} \mathrm{~F}\right)_{4}^{-} \\
2 \mathrm{SbF}_{2}\left(\mathrm{SO}_{3} \mathrm{~F}\right)_{3}+2 \mathrm{HSO}_{3} \mathrm{~F}=\mathrm{H}_{2} \mathrm{SO}_{3} \mathrm{~F}^{+}+\left[\mathrm{SbF}_{2}\left(\mathrm{SO}_{3} \mathrm{~F}\right)_{3}\right]_{2} \mathrm{SO}_{3} \mathrm{~F}^{-} \\
{\left[\mathrm{SbF}_{2}\left(\mathrm{SO}_{3} \mathrm{~F}\right)_{3}\right]_{2} \mathrm{SO}_{3} \mathrm{~F}^{-}+2 \mathrm{HSO}_{3} \mathrm{~F} \stackrel{K_{3}}{=} \mathrm{H}_{2} \mathrm{SO}_{3} \mathrm{~F}^{+}+2 \mathrm{SbF}_{2}\left(\mathrm{SO}_{3} \mathrm{~F}\right)_{4}^{-}} \\
K_{3}=4 \times 10^{-3} \mathrm{~mol}^{2} \mathrm{~kg}^{-2}
\end{gathered}
$$

A number of other covalent fluorides have been shown to behave as acids in fluorosulphuric acid, but all are much weaker than antimony pentafluo$\mathrm{ride}^{29}$. The addition of sulphur trioxide, up to the mole ratio $\mathrm{SO}_{3} / \mathrm{AsF}_{5}=3.0$ considerably enhanced the acidity of solutions of arsenic pentafluoride, but had no effect on acidity in the other cases studied. In this case also, insertion of sulphur trioxide into up to three As-F bonds can occur, and substitution of fluorosulphate for fluoride increases the acid strength. The order of acid strengths was found, from conductivity measurements, to be: $\mathrm{PF}_{5} \sim \mathrm{NbF}_{5}$ $<\mathrm{TiF}_{4} \sim \mathrm{AsF}_{5}<\mathrm{BiF}_{5}<\mathrm{AsF}_{4} \mathrm{SO}_{3} \mathrm{~F}<\mathrm{SbF}_{4}<\mathrm{AsF}_{2}\left(\mathrm{SO}_{3} \mathrm{~F}\right)_{3}<\mathrm{SbF}_{2}\left(\mathrm{SO}_{3} \mathrm{~F}\right)_{3}$. Phosphorus and niobium pentafluorides showed no acidic behaviour detectable by conductivity measurements, although recent acidity function measurements have shown niobium pentafluoride to be an extremely weak $\operatorname{acid}^{30}$.

Several covalent fluorides behave as acids, i.e. fluoride ion acceptors, in anhydrous hydrogen fluoride. The same general order of acid strengths prevails as in fluorosulphuric acid, namely: $\mathrm{TiF}_{4} \sim \mathrm{SnF}_{4}<\mathrm{BF}_{3}<\mathrm{PF}_{5}<$ $\mathrm{NbF}_{5}<\mathrm{TaF}_{5}<\mathrm{AsF}_{5}<\mathrm{SbF}_{5}{ }^{19,31}$, but since hydrogen fluoride is a more basic solvent than fluorosulphuric acid, the extent of ionization of any given fluoride tends to be greater. Thus, antimony pentafluoride, which is rather a weak acid in fluorosulphuric acid, has been shown to be fully ionized as an acid in hydrogen fluoride ${ }^{32}$ :

$$
\mathrm{SbF}_{5}+2 \mathrm{HF}=\mathrm{H}_{2} \mathrm{~F}^{+}+\mathrm{SbF}_{6}^{-}
$$

In dilute solutions only a single ${ }^{19} \mathrm{~F}$ n.m.r. signal is observed, assigned to the $\mathrm{SbF}_{6}^{-}$ion, while in more concentrated solutions, the low-temperature spectrum can be interpreted in terms of $\mathrm{SbF}_{6}^{-}$and the fluorine-bridged dimer, $\mathrm{Sb}_{2} \mathrm{~F}_{11}^{-}$. In still more concentrated solutions higher polymers, such as $\mathrm{Sb}_{3} \mathrm{~F}_{16}^{-}$, occur:

$$
\begin{aligned}
& 2 \mathrm{SbF}_{5}+2 \mathrm{HF}=\mathrm{H}_{2} \mathrm{~F}^{+}+\mathrm{Sb}_{2} \mathrm{~F}_{11}^{-} \\
& 3 \mathrm{SbF}_{5}+2 \mathrm{HF}=\mathrm{H}_{2} \mathrm{~F}^{+}+\mathrm{Sb}_{3} \mathrm{~F}_{16}^{-}
\end{aligned}
$$




\section{STRONGLY ACIDIC SOLVENT MEDIA}

\section{ACIDITY FUNCTIONS}

The Hammett acidity function, $H_{0}$, is defined operationally by the equation:

$$
H_{0}=\mathrm{p} K_{\mathrm{a}}-\log \left[\mathrm{BH}^{+}\right] /[\mathrm{B}]
$$

where $\mathrm{BH}^{+}$and $\mathrm{B}$ are the protonated and unprotonated forms of an indicator base, and $\mathrm{p} K_{\mathrm{a}}$ for the indicator is referred to the standard state in water. It is now recognized that the protonation of different types of base is described by different acidity functions ${ }^{3}$, but the $H_{0}$ function, defined by the use of primary anilines as indicators, continues to be the most widely used measure of the acidity of strongly acidic media.

Although much use has been made of the ability of super-acid media to protonate very weak bases, the only acidity function data available for such systems, until very recently, were those of Brand et al. ${ }^{34}$ for oleums, and of Palm for the system $\mathrm{H}_{2} \mathrm{SO}_{4}-\mathrm{HSO}_{3} \mathrm{Cl}^{35}$. Gillespie $e$ al. have recently published $H_{0}$ data for a number of systems, in sulphuric and fluorosulphuric acids as solvents ${ }^{36,37}$. Although the $H_{0}$ function proper is based on primary anilines as indicators, it is difficult to find primary anilines which are weak enough bases for use in very acidic media, and a series of aromatic nitro-compounds were used to extend the scale into the super-acid region. In the most acidic solutions studied, no sufficiently weak neutral base was available, and the second protonations of some polynitro-compounds were used to establish the scale. Strictly speaking the acidity function thus obtained is an $H_{+}$ function, and values of $-H_{0}$ greater than 17 are regarded as less reliable than lower values. Figures 1 and 2 show the results obtained. Table 3 shows $H_{0}$ values for some acids.

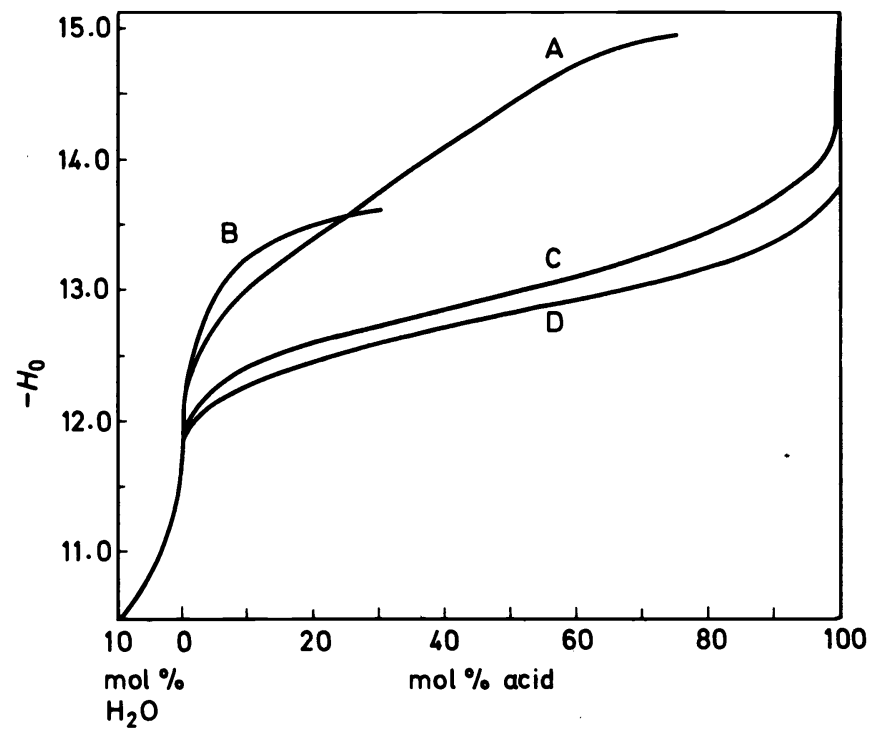

Figure 1. $\mathrm{H}_{0}$ values for the systems: $\mathrm{H}_{2} \mathrm{O}-\mathrm{H}_{2} \mathrm{SO}_{4}-\mathrm{SO}_{3}(\mathrm{~A}), \mathrm{H}_{2} \mathrm{SO}_{4}-\mathrm{HB}\left(\mathrm{HSO}_{4}\right)_{4}(\mathrm{~B}), \mathrm{H}_{2} \mathrm{SO}_{4}-$ $\mathrm{HSO}_{3} \mathrm{~F}(\mathrm{C}), \mathrm{H}_{2} \mathrm{SO}_{4}-\mathrm{HSO}_{3} \mathrm{Cl}(\mathrm{D})$ 


\section{JOHN B. SENIOR}

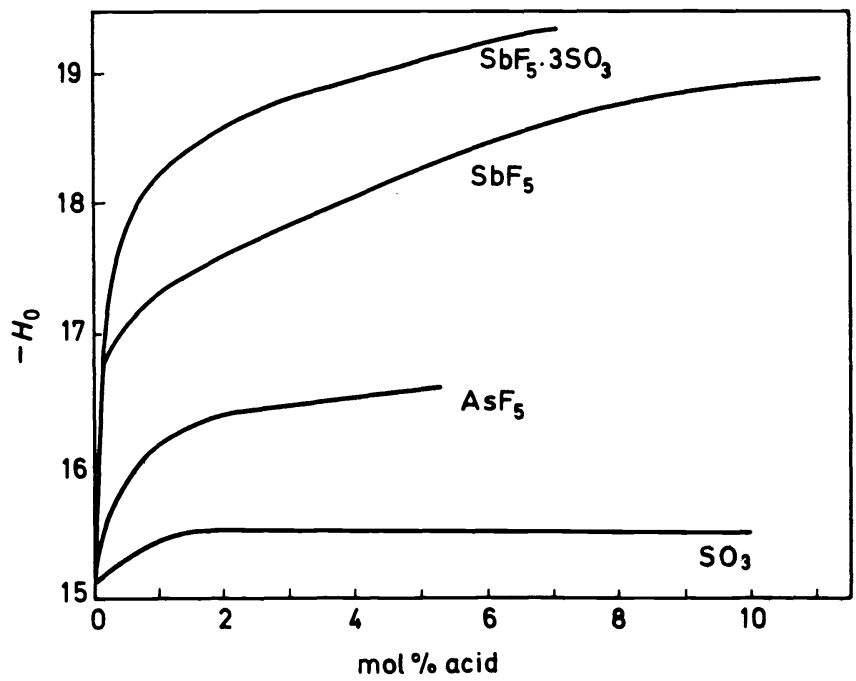

Figure 2. $H_{0}$ values for acids in fluorosulphuric acid

Table 3. $H_{0}$ values for some acids

\begin{tabular}{llc}
\hline \multicolumn{1}{c}{ Acid } & $-H_{0}$ & Reference \\
\hline $\mathrm{HF}$ & 11 & 31 \\
$\mathrm{H}_{2} \mathrm{SO}_{4}$ & 11.93 & 36 \\
$\mathrm{HSO}_{3} \mathrm{Cl}$ & 13.80 & 36 \\
$\mathrm{H}_{2} \mathrm{~S}_{2} \mathrm{O}_{7}$ & 14.44 & 36 \\
$\mathrm{HSO}_{3} \mathrm{~F}$ & 15.07 & 37 \\
$\mathrm{HSO}_{3} \mathrm{~F}\left(10 \% \mathrm{SbF}_{5}\right)$ & 18.94 & 37 \\
$\mathrm{HSO}_{3} \mathrm{~F}\left(7 \% \mathrm{SbF}_{5} .3 \mathrm{SO}_{3}\right)$ & 19.35 & 37 \\
\hline
\end{tabular}

The rapid increase in acidity in the immediate vicinity of the compositions $100 \% \mathrm{H}_{2} \mathrm{SO}_{4}$ and $100 \% \mathrm{HSO}_{3} \mathrm{~F}$, arising from rapid changes in concentrations of the solvent autoprotolysis ions, should be noted. At higher concentrations of base or acid the solùtions are buffered, and $H_{0}$ changes more slowly with concentration. The curves are analogous to the familiar $\mathrm{pH}$ titration curves for acids and bases in aqueous solution. No rapid change in acidity occurs at the composition $\mathrm{H}_{2} \mathrm{~S}_{2} \mathrm{O}_{7}$, where extensive self-dissociation leads to a highly baffered system. The value of $H_{0}$ for fluorosulphuric acid could not be measured directly, because even the very low concentration of indicator base required produced sufficient fluorosulphate ion to disturb the autoprotolysis equilibrium and reduce the concentration of the $\mathrm{H}_{2} \mathrm{SO}_{3} \mathrm{~F}^{+}$ion to a value appreciably below that in the pure solvent. The $H_{0}$ value of -15.07 for pure fluorosulphuric acid was derived by extrapolation of the data for the $\mathrm{H}_{2} \mathrm{SO}_{4}-\mathrm{HSO}_{3} \mathrm{~F}$ system. From their respective $H_{0}$ values it appears that fluorosulphuric acid $\left(-H_{0}=15.07\right)$ is a stronger acid than disulphuric acid $\left(-H_{0}=14.44\right)$. However, at the higher solute concentrations used in cryoscopic and conductimetric studies, weak bases are found to be more 
extensively ionized in disulphuric acid than in fluorosulphuric acid, because while the acidity of the latter solvent is greatly reduced by the added base, that of the highly buffered disulphuric acid is hardly affected.

It can be seen from the $H_{0}$-composition curves that fluorodisulphuric acid, formed in solutions of sulphur trioxide in fluorosulphuric acid, does in fact behave as an extremely weak acid, although its ionization could not be detected by conductimetric means. Arsenic pentafluoride is a somewhat stronger acid, in agreement with conductimetric data, and antimony pentafluoride is stronger still. In both these cases the acidity increases more than might have been expected at higher concentrations, owing to the formation of the dimeric anions, $\left(\mathrm{MF}_{5}\right)_{2} \mathrm{SO}_{3} \mathrm{~F}^{-}$, whose parent acids are stronger than the monomers.

The strong acid, $\mathrm{SbF}_{2}\left(\mathrm{SO}_{3} \mathrm{~F}\right)_{3}$, gives, as expected, still more acidic solutions. The value of $-H_{0}$ for a $7 \mathrm{~mol} \%$ solution of this acid is 19.3 , the highest value so far measured.

Just as, by definition, in very dilute aqueous solution, $\mathrm{H}_{0} \approx-\log \left[\mathrm{H}_{3} \mathrm{O}^{+}\right]$, so it might be anticipated that in the immediate vicinity of the compositions of pure sulphuric acid or fluorosulphuric acid, $H_{0}$ would be a log function of the concentration of $\mathrm{H}_{3} \mathrm{SO}_{4}^{+}$or $\mathrm{H}_{2} \mathrm{SO}_{3} \mathrm{~F}^{+}$, respectively. The relation:

$$
H_{0}=-\log \left[\mathrm{H}_{3} \mathrm{SO}_{4}^{+}\right]-13.95
$$

was in agreement with experimental data for very dilute solutions of water or sulphur trioxide in sulphuric $\mathbf{a c i d}^{38}$, and the relation:

$$
H_{0}=-\log \left[\mathrm{H}_{2} \mathrm{SO}_{3} \mathrm{~F}^{+}\right]-18.79
$$

has been proposed for dilute solutions of acids or bases in fluorosulphuric $\operatorname{acid}^{37}$. By the use of the latter expression, approximate $K_{\mathrm{a}}$ values for the weak acids in fluorosulphuric acid have been derived from acidity function data, as follows: $\mathrm{SbF}_{5}, 2.2 \times 10^{-3}$ (cf. $3.7 \times 10^{-3}$ from conductivity); $\mathrm{AsF}_{5}, 3.7 \times$ $10^{-6} ; \mathrm{HS}_{2} \mathrm{O}_{6} \mathrm{~F}, 4.6 \times 10^{-7} \mathrm{~mol} \mathrm{~kg}^{-1}$. Very recent acidity function measurements show that niobium pentafluoride behaves as an extremely weak acid in fluorosulphuric acid. while tantalum pentafluoride is a slightly weaker acid than arsenic pentafluoride ${ }^{30}$.

Recent, unpublished measurements ${ }^{30}$ of the $H_{0}$ function for dilute solutions of antimony pentafluoride in hydrogen fluoride (up to $0.4 \mathrm{~mol}^{\%} \mathrm{SbF}_{5}$ ) show that, at very low concentrations, the acidity increases very rapidly with increasing concentration, because of the very small extent of self-dissociation of hydrogen fluoride. The $H_{0}$-concentration curve then runs approximately parallel to the curve for antimony pentafluoride in fluorosulphuric acid, but at $H_{0}$ values about two units less negative. It seems reasonable that antimony pentafluoride should, as found, give more acidic solutions in fluorosulphuric acid, in which it is only partly ionized, than in hydrogen fluoride, in which it is fully ionized and its acid strength is levelled to that of the $\mathrm{H}_{2} \mathrm{~F}^{+}$ion. Furthermore, since substitution of fluorosulphate for fluoride has been shown to enhance acid strength, the un-ionized $\mathrm{H}\left[\mathrm{SbF}_{5}\left(\mathrm{SO}_{3} \mathrm{~F}\right)\right]$ should be inherently a stronger acid than $\mathrm{HSbF}_{6}$. It is therefore all the more surprising that in a series of recent studies by Brouwer et al. ${ }^{39}$ it has been found that rearrangement reactions such as: 
JOHN B. SENIOR

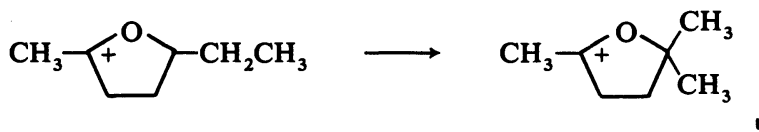

which proceed via doubly protonated intermediates, and occur only in super-acid media, are very much faster in $\mathrm{HF}-\mathrm{SbF}_{5}$ media than in $\mathrm{HSO}_{3} \mathrm{~F}-$ $\mathrm{SbF}_{5}$. From the rates of the above and related reactions, the following order of relative acidities has been derived:

$$
\begin{array}{lc}
\text { 1: } 1 \mathrm{HF}-\mathrm{SbF}_{5} & >500 \\
\text { 9: } 1 \mathrm{HF}-\mathrm{SbF}_{5} & 1 \\
\text { 1: } 1 \mathrm{HSO}_{3} \mathrm{~F}-\mathrm{SbF}_{5} & 10^{-1} \\
\text { 5: } 1 \mathrm{HSO}_{3} \mathrm{~F}-\mathrm{SbF}_{5} & 10^{-5}
\end{array}
$$

It would probably not be profitable at present to speculate on the reasons for this apparently discrepant behaviour. These results do, however, serve as a warning that estimates of acidity based on the $H_{0}$ function may prove to be very misleading in other applications. Clearly it will be important to extend acidity function measurements to still higher acid concentrations, and to study the protonation behaviour of different types of bases in these super-acid media.

\section{NOVEL POLYATOMIC CATIONS IN STRONG ACID MEDIA}

Strong acid solvents have been extensively used in recent years in studies of polyatomic cations, especially those of the elements of Groups VI and VII, many of which are stable in solution only in super-acid media.

\section{HALOGEN CATIONS 40}

The brown solutions formed by the oxidation of iodine with iodic acid or iodine pentoxide in concentrated sulphuric acid were long believed on chemical grounds to contain the cations $\mathrm{I}_{3}^{+}$and $\mathrm{I}_{5}^{+}$. This has been confirmed by cryoscopic ${ }^{41}$ and conductimetric ${ }^{41,42}$ studies in $100 \%$ sulphuric acid:

$$
\begin{gathered}
\mathrm{HIO}_{3}+7 \mathrm{I}_{2}+8 \mathrm{H}_{2} \mathrm{SO}_{4}=5 \mathrm{I}_{3}^{+}+3 \mathrm{H}_{3} \mathrm{O}^{+}+8 \mathrm{HSO}_{4}^{-} \\
\mathrm{I}_{3}^{+}+\mathrm{I}_{2}=\mathrm{I}_{5}^{+}
\end{gathered}
$$

These cations have also been characterized in fluorosulphuric acid ${ }^{43}$. The preparation and n.q.r. spectra of the solid compounds $\mathrm{I}_{3}^{+} \mathrm{AlCl}_{4}^{-}$and $\mathrm{I}_{5}^{+} \mathrm{AlCl}_{4}^{-}$ have recently been reported ${ }^{44}$. Cryoscopic and conductimetric evidence has also been presented for the formation of the interhalogen cations, $\mathrm{ICl}_{2}^{+}$and $\mathrm{IBr}_{2}^{+45}$, and of the unsymmetrical species, $\mathrm{I}_{2} \mathrm{Cl}^{+}$and $\mathrm{I}_{2} \mathrm{Br}^{+41}$, in $100 \%$ sulphuric acid:

$$
\begin{aligned}
& \mathrm{HIO}_{3}+2 \mathrm{I}_{2}+5 \mathrm{X}_{2}+8 \mathrm{H}_{2} \mathrm{SO}_{4}=5 \mathrm{IX}_{2}^{+}+3 \mathrm{H}_{3} \mathrm{O}^{+}+8 \mathrm{HSO}_{4}^{-} \\
& \mathrm{HIO}_{3}+2 \mathrm{I}_{2}+5 \mathrm{IX}+8 \mathrm{H}_{2} \mathrm{SO}_{4}=5 \mathrm{I}_{2} \mathrm{X}^{+}+3 \mathrm{H}_{3} \mathrm{O}^{+}+8 \mathrm{HSO}_{4}^{-}
\end{aligned}
$$

$$
(\mathrm{X}=\mathrm{Cl}, \mathrm{Br} \text { ) }
$$


The $\mathrm{ICl}_{2}^{+}$cation is known in the solid compounds $\mathrm{ICl}_{2}^{+} \mathrm{AlCl}_{4}^{-}$and $\mathrm{ICl}_{2}^{+} \mathrm{SbCl}_{6}^{-}$in which it has been shown to have an angular structure ${ }^{46}$, and has also been obtained in solutions of iodine trichloride in disulphuric acid ${ }^{47}$ :

$$
\mathrm{ICl}_{3}+3 \mathrm{H}_{2} \mathrm{~S}_{2} \mathrm{O}_{7}=\mathrm{ICl}_{2}^{+}+\mathrm{HClSO}_{3}+2 \mathrm{H}_{2} \mathrm{SO}_{4}+\mathrm{HS}_{3} \mathrm{O}_{10}^{-}
$$

It has been suggested that the unsymmetrical cations might undergo disproportionation in solution to give the symmetrical cations ${ }^{40,41}$ :

$$
2 \mathrm{I}_{2} \mathrm{X}^{+} \rightleftharpoons \mathrm{IX}_{2}^{+}+\mathrm{I}_{3}^{+}
$$

Very recently the solid compounds $\mathrm{I}_{2} \mathrm{Cl}^{+} \mathrm{SbCl}_{6}^{-}$and $\mathrm{IBrCl}^{+} \mathrm{SbCl}_{6}^{-}$have been prepared in the reactions ${ }^{48,49}$ :

$$
\begin{aligned}
\mathrm{I}_{2}+\mathrm{Cl}_{2}+\mathrm{SbCl}_{5} & =\mathrm{I}_{2} \mathrm{Cl}^{+} \mathrm{SbCl}_{6}^{-} \\
\mathrm{IBr}+\mathrm{Cl}_{2}+\mathrm{SbCl}_{5} & =\mathrm{IBrCl}^{+} \mathrm{SbCl}_{6}^{-}
\end{aligned}
$$

Their Raman spectra support the ionic formulations, and the structures $\mathrm{I}-\stackrel{+}{\mathrm{I}}-\mathrm{Cl}$ and $\mathrm{Br}-\stackrel{+}{\mathrm{I}}-\mathrm{Cl}$ (probably bent, by analogy with $\mathrm{ICl}_{2}^{+}$) for the cations. NQR studies of the $\mathrm{ICl}-\mathrm{AlCl}_{3}$ system have shown the existence of the compound $\mathrm{I}_{2} \mathrm{Cl}^{+} \mathrm{AlCl}_{4}^{-44}$. The fluorosulphates of a series of triatomic halogen cations have also recently been prepared ${ }^{50}$ :

$$
\begin{array}{ll}
\mathrm{ISO}_{3} \mathrm{~F}+\mathrm{X}_{2}=\mathrm{IX}_{2} \mathrm{SO}_{3} \mathrm{~F} & (\mathrm{X}=\mathrm{Cl}, \mathrm{Br}, \mathrm{I}) \\
\mathrm{ISO}_{3} \mathrm{~F}+\mathrm{IX}=\mathrm{I}_{2} \mathrm{XSO}_{3} \mathrm{~F} & (\mathrm{X}=\mathrm{Cl}, \mathrm{Br})
\end{array}
$$

Conductimetric studies showed that these compounds were all fully ionized in fluorosulphuric acid, e.g.:

$$
\mathrm{IBr}_{2} \mathrm{SO}_{3} \mathrm{FSO}_{3} \mathrm{HBr}_{2}^{+}+\mathrm{SO}_{3} \mathrm{~F}^{-}
$$

Vibrational spectra of the solids showed the presence of essentially ionic fluorosulphate groups, and supported the unsymmetrical structures, $\mathrm{I}-\mathrm{I}-\mathrm{X}$, for the $\mathrm{I}_{2} \mathrm{X}^{+}$cations. The existence of the unsymmetrical cations in the solid state may thus be regarded as established. Detailed studies of u.v:visible absorption spectra indicate further that these ions are by no means fully disproportionated in solution ${ }^{50}$.

While the species so far mentioned are stable even in relatively basic media such as $97 \%$ sulphuric acid, other halogen cations can be obtained in solution only in super-acid media.

Solutions of iodine in concentrated oleums contain a blue paramagnetic species which was for a long time believed to be the cation $\mathrm{I}^{+51}$. It was first shown conclusively by Gillespie and Milne in $1966^{52}$, by spectrophotometric, conductimetric and magnetic susceptibility measurements, that this species is in fact the diatomic cation, $\mathrm{I}_{2}^{+}$. When iodine was oxidized with peroxodisulphuryl difluoride in fluorosulphuric acid, the concentration of the iodine cation reached its maximum at the mole ratio $\mathrm{I}_{2} / \mathrm{S}_{2} \mathrm{O}_{6} \mathrm{~F}_{2}=2.0$, corresponding to the reaction:

$$
2 \mathrm{I}_{2}+\mathrm{S}_{2} \mathrm{O}_{6} \mathrm{~F}_{2}=2 \mathrm{I}_{2}^{+}+2 \mathrm{SO}_{3} \mathrm{~F}^{-}
$$

The diiodine cation is in fact partly disproportionated in this medium:

$$
8 \mathrm{I}_{2}^{+}+3 \mathrm{SO}_{3} \mathrm{~F}^{-} \rightleftharpoons \mathrm{I}\left(\mathrm{SO}_{3} \mathrm{~F}\right)_{3}+5 \mathrm{I}_{3}^{+}
$$


Disproportionation can be prevented by the addition of antimony pentafluoride, which reduces the basicity of the medium by combining with fluorosulphate ion. In $100 \%$ sulphuric acid the disproportionation of $\mathrm{I}_{2}^{+}$to $\mathrm{I}_{3}^{+}$and an iodine(III) species is essentially complete.

A reinvestigation of the blue solutions of iodine in oleums ${ }^{47}$ has confirmed the formation of $\mathrm{I}_{2}^{+}$, which in $65 \%$ oleum may be represented by:

$$
2 \mathrm{I}_{2}+5 \mathrm{SO}_{3}+\mathrm{H}_{2} \mathrm{~S}_{4} \mathrm{O}_{13}=2 \mathrm{I}_{2}^{+}+2 \mathrm{HS}_{4} \mathrm{O}_{13}^{-}+\mathrm{SO}_{2}
$$

Crystalline solids, formulated as $\mathrm{I}_{2}^{+} \mathrm{Sb}_{2} \mathrm{~F}_{11}^{-}$and $\mathrm{I}_{2}^{+} \mathrm{Ta}_{2} \mathrm{~F}_{11}^{-}$have been obtained by Kemmitt et al. ${ }^{53}$, who have also studied blue solutions of the diiodine cation in antimony pentafluoride and in iodine pentafluoride.

At temperatures close to the freezing point of fluorosulphuric acid $\left(-90^{\circ} \mathrm{C}\right)$, $\mathrm{I}_{2}^{+}$dimerizes to the intensely red-brown coloured, diamagnetic cation, $\mathrm{I}_{4}^{2+54}$ :

$$
2 \mathrm{I}_{2}^{+} \rightleftharpoons \mathrm{I}_{4}^{2+}
$$

A much more weakly basic medium is required in order to stabilize bromine cations. The red-brown $\mathrm{Br}_{3}^{+}$can be produced by the oxidation of bromine with peroxodisulphuryl difluoride in fluorosulphuric acid ${ }^{14}$ :

$$
3 \mathrm{Br}_{2}+\mathrm{S}_{2} \mathrm{O}_{6} \mathrm{~F}_{2}=2 \mathrm{Br}_{3}^{+}+2 \mathrm{SO}_{3} \mathrm{~F}^{-}
$$

It is, however, not completely stable in this medium, and exists in equilibrium with bromine and bromine(I)fluorosulphate:

$$
\mathrm{Br}_{3}^{+}+\mathrm{SO}_{3} \mathrm{~F}^{-} \rightleftharpoons \mathrm{Br}_{2}+\mathrm{BrSO}_{3} \mathrm{~F}
$$

In a solution of $\mathrm{SbF}_{2}\left(\mathrm{SO}_{3} \mathrm{~F}\right)_{3}$ in fluorosulphuric acid, $\mathrm{Br}_{3}^{+}$is not disproportionated, and can be oxidized further to the cherry-red $\mathrm{Br}_{2}^{+}$:

$$
4 \mathrm{Br}_{3}^{+}+\mathrm{S}_{2} \mathrm{O}_{6} \mathrm{~F}_{2}=6 \mathrm{Br}_{2}^{+}+2 \mathrm{SO}_{3} \mathrm{~F}^{-}
$$

Both bromine cations have been obtained in solid compounds. The compound $\mathrm{Br}_{3}^{+} \mathrm{AsF}_{6}^{-}$was prepared by the oxidation of bromine with $\mathrm{O}_{2}^{+} \mathrm{AsF}_{6}^{-}{ }^{55}$ :

$$
3 \mathrm{Br}_{2}+2 \mathrm{O}_{2}^{+} \mathrm{AsF}_{6}^{-}=2 \mathrm{Br}_{3}^{+} \mathrm{AsF}_{6}^{-}+2 \mathrm{O}_{2}
$$

At the same time that the dibromine cation was first characterized in solution, Edwards et al. ${ }^{56}$ reported the preparation of the compound $\mathrm{Br}_{2}^{+} \mathrm{Sb}_{3} \mathrm{~F}_{16}^{-}$, and determined its crystal structure.

$$
9 \mathrm{Br}_{2}+2 \mathrm{BrF}_{5}+30 \mathrm{SbF}_{5}=10 \mathrm{Br}_{2}^{+} \mathrm{Sb}_{3} \mathrm{~F}_{16}^{-}
$$

The corresponding chlorine cations are even more unstable, and neither $\mathrm{Cl}_{3}^{+}$nor $\mathrm{Cl}_{2}^{+}$could be obtained even in solutions of chlorine and chlorine(I) fluorosulphate in the most acidic medium available, namely $\mathrm{SbF}_{2}\left(\mathrm{SO}_{3} \mathrm{~F}\right)_{3}$ in fluorosulphuric acid ${ }^{57}$. Earlier claims to have obtained the $\mathrm{Cl}_{2}^{+}$cation in less acidic media ${ }^{58}$ seem to have been in error ${ }^{40}$. The solid $\mathrm{Cl}_{3}^{+} \mathrm{AsF}_{6}^{-}$has, however, been prepared at $-76^{\circ} \mathrm{C}$ by the reaction ${ }^{59}$ :

$$
\mathrm{Cl}_{2}+\mathrm{ClF}+\mathrm{AsF}_{5}=\mathrm{Cl}_{3}^{+} \mathrm{AsF}_{6}^{-}
$$

It is completely decomposed at room temperature. An analysis of the vibrational spectrum of this compound suggests a bent structure for $\mathrm{Cl}_{3}^{+}$, with a bond angle of about $100^{\circ}$. 


\section{CATIONS OF GROUP VI ELEMENTS ${ }^{60}$}

The long-standing controversy over the nature of the species present in the coloured solutions formed by sulphur, selenium and tellurium in sulphuric acid and oleums has been largely settled within the last few years by the characterization of a number of polyatomic cations of these elements, in solution in strong acids and in the solid state. In general, it has proved more convenient to study these ions in solution in fluorosulphuric acid rather than in the more complex and more strongly oxidizing oleums.

Tellurium dissolves in fluorosulphuric acid to give red solutions, shown by conductivity measurements to contain tellurium in the formal oxidation state $+\frac{1}{2}^{61}$. Solutions with the same spectrum were obtained by the reaction of tellurium and tellurium tetrachloride in molten $\mathrm{NaCl}-\mathrm{AlCl}_{3}{ }^{62}$. A number of solids containing the red species have been obtained, e.g. $\mathrm{Te}_{4}\left(\mathrm{Sb}_{2} \mathrm{~F}_{11}\right)_{2}$, $\mathrm{Te}_{4}\left(\mathrm{AsF}_{6}\right)_{2}, \mathrm{Te}_{4}\left(\mathrm{SO}_{3} \mathrm{~F}\right)_{2}$ and $\mathrm{Te}_{4} \mathrm{~S}_{3} \mathrm{O}_{10}{ }^{63,64,65}$ and the crystal structures of two of them, $\mathrm{Te}_{4}\left(\mathrm{AlCl}_{4}\right)_{2}$ and $\mathrm{Te}_{4}\left(\mathrm{Al}_{2} \mathrm{Cl}_{7}\right)_{2}$, have been determined ${ }^{66}$. They contain the square planar $\mathrm{Te}_{4}^{2+}$ cation, with a Te-Te bond distance of $2.76 \AA$. This confirmed previous identification of this species based on similarities of its u.v.-visible, and Raman spectra and magnetic circular dichroism ${ }^{67}$ to those of the $\mathrm{Se}_{4}^{2+}$ ion.

Further oxidation of tellurium in fluorosulphuric acid with peroxodisulphuryl difluoride gives yellow solutions containing tellurium in the +1 oxidation state ${ }^{63,64}$. The species present may be formulated as $\mathrm{Te}_{n}^{n+}$, where $n$ remains uncertain. Solids of empirical formula $\mathrm{TeSbF}_{6}, \mathrm{TeSO}_{3} \mathrm{~F}$ and $\mathrm{Te}_{2} \mathrm{~S}_{3} \mathrm{O}_{10}$, containing this species have been obtained ${ }^{63,64,65}$. They are diamagnetic, so that $n$ must be even. Cryoscopic measurements in fluorosulphuric acid are said to rule out $\mathrm{Te}_{2}^{2+}$, while not distinguishing with certainty between $n=4,6$ or $8^{63,64}$. On the other hand, cryoscopic studies of yellow solutions of tellurium in disulphuric acid have been claimed ${ }^{65}$ to support the formulation $\mathrm{Te}_{2}^{2+}$, and a tellurium(I) species present in solutions formed by the reduction of tellurium tetrachloride (in large excess) with tellurium in molten $\mathrm{KAlCl}_{4}$ buffered with $\mathrm{KCl}-\mathrm{ZnCl}_{2}$ at $300^{\circ} \mathrm{C}$, has also been claimed ${ }^{68}$ to be $\mathrm{Te}_{2}^{2+}$.

Black solids, $\left(\mathrm{Te}_{3} \mathrm{AsF}_{6}\right)_{n}$ and $\left(\mathrm{Te}_{3} \mathrm{AlCl}_{4}\right)_{n}$ have been obtained ${ }^{64,69}$. The latter is diamagnetic and since the size of its unit cell shows that $n$ cannot be greater than two, it is formulated ${ }^{69}$ as $\mathrm{Te}_{6}^{2+}\left(\mathrm{AlCl}_{4}^{-}\right)_{2}$. No evidence for the structure of the $\mathrm{Te}_{6}^{2+}$ cation is yet available.

When selenium is oxidized with peroxodisulphuryl difluoride in fluorosulphuric acid, the solutions are first green, then yellow, and finally colourless ${ }^{70}$. By photometric titration and conductimetric and cryoscopic measurements, the yellow species was shown to be $\mathrm{Se}_{4}^{2+}$, formed in the reaction:

$$
4 \mathrm{Se}+\mathrm{S}_{2} \mathrm{O}_{6} \mathrm{~F}_{2}=\mathrm{Se}_{4}^{2+}+2 \mathrm{SO}_{3} \mathrm{~F}^{-}
$$

Addition of selenium to these solutions, up to the mole ratio $\mathrm{Se} / \mathrm{S}_{2} \mathrm{O}_{6} \mathrm{~F}_{2}=$ 8.0 , gives the green species $\mathrm{Se}_{8}^{2+}$ :

$$
\mathrm{Se}_{4}^{2+}+4 \mathrm{Se}=\mathrm{Se}_{8}^{2+}
$$

Selenium can also be oxidized in fluorosulphuric acid alone at room temperature, and in sulphuric acid at $50-60^{\circ} \mathrm{C}$ to give $\mathrm{Se}_{8}^{2+}$. In disulphuric 
acid, selenium undergoes successive oxidation by the solvent, first to $\mathrm{Se}_{8}^{2+}$ and then to $\mathrm{Se}_{4}^{2+}$.

A number of solid compounds containing selenium cations have been isolated, e.g. $\quad \mathrm{Se}_{4}\left(\mathrm{HS}_{2} \mathrm{O}_{7}\right)_{2}, \quad \mathrm{Se}_{4} \mathrm{~S}_{4} \mathrm{O}_{13}, \quad \mathrm{Se}_{4}\left(\mathrm{SO}_{3} \mathrm{~F}\right)_{2}, \quad \mathrm{Se}_{4}\left(\mathrm{Sb}_{2} \mathrm{~F}_{11}\right)_{2}{ }_{71}$, $\mathrm{Se}_{4}\left(\mathrm{AsF}_{6}\right)_{2}{ }^{60}, \mathrm{Se}_{4}\left(\mathrm{AlCl}_{4}\right)_{2}{ }^{74}, \mathrm{Se}_{8}\left(\mathrm{Sb}_{2} \mathrm{~F}_{11}\right)_{2}, \mathrm{Se}_{8}\left(\mathrm{AsF}_{6}\right)_{2}$ and $\mathrm{Se}_{8}\left(\mathrm{AlCl}_{4}\right)_{2}{ }_{73}$. $\mathrm{X}$-ray crystallographic studies of $\mathrm{Se}_{4}\left(\mathrm{HS}_{2} \mathrm{O}_{7}\right)_{2}$ have shown that $\mathrm{Se}_{4}^{2+}$ is square planar, with an $\mathrm{Se}-\mathrm{Se}$ bond distance of $2.28 \AA$. The crystal structure of $\mathrm{Se}_{8}\left(\mathrm{AlCl}_{4}\right)_{2}$ has also been determined ${ }^{73}$ and it has been shown that the $\mathrm{Se}_{8}^{2+}$ cation has the endo, exo bridged ring structure $\mathrm{V}$.

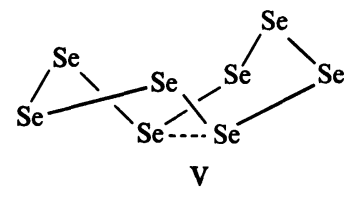

Oxidation of sulphur in fluorosulphuric acid with peroxodisulphuryl difluoride gives successive red, blue and pale yellow solutions ${ }^{75}$. Conductimetric and cryoscopic studies show that the red solutions contain the cation $\mathrm{S}_{16}^{2+}$ :

$$
2 \mathrm{~S}_{8}+\mathrm{S}_{2} \mathrm{O}_{6} \mathrm{~F}_{2}=\mathrm{S}_{16}^{2+}+2 \mathrm{SO}_{3} \mathrm{~F}^{-}
$$

This cation is also produced in solutions of sulphur in $5 \%$ oleum $^{76}$. These solutions give an e.s.r. signal at $g=2.027$, which has been assigned to the radical cation $S_{8}^{+}$present in small concentrations in equilibrium with $S_{16}^{2+}$. The solid compounds $\mathrm{S}_{16}\left(\mathrm{AsF}_{6}\right)_{2}$ and $\mathrm{S}_{16}\left(\mathrm{SbF}_{6}\right)_{2}$ have been prepared ${ }^{75}$, but unfortunately their crystal structures have not yet been reported.

At the mole ratio $\mathrm{S}_{8} / \mathrm{S}_{2} \mathrm{O}_{6} \mathrm{~F}_{2}=1.0$ in fluorosulphuric acid, blue solutions are formed, containing the $\mathrm{S}_{8}^{2+}$ cation ${ }^{75}$. The solutions are unstable and deposit sulphur on standing. Compounds containing the $\mathrm{S}_{8}^{2+}$ ion have been prepared by the reactions ${ }^{75}$ :

$$
\begin{aligned}
& \mathrm{S}_{8}+3 \mathrm{AsF}_{5} \stackrel{\mathrm{HF}}{\longrightarrow} \mathrm{S}_{8}\left(\mathrm{AsF}_{6}\right)_{2}+\mathrm{AsF}_{3} \\
& \mathrm{~S}_{8}+5 \mathrm{SbF}_{5} \stackrel{\mathrm{SO}_{2}}{\longrightarrow} \mathrm{S}_{8}\left(\mathrm{Sb}_{2} \mathrm{~F}_{11}\right)_{2}+\mathrm{SbF}_{3}
\end{aligned}
$$

The crystal structure of $\mathrm{S}_{8}\left(\mathrm{AsF}_{6}\right)_{2}$ has been determined ${ }^{77}$. The $\mathrm{S}_{8}^{2+}$ cation has the folded ring structure VI with an endo, exo conformation, and a rather long bond across the middle of the ring.

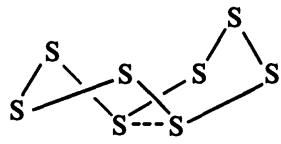

VI

A paramagnetic species, giving an e.s.r. signal at $g=2.014$ is associated with $\mathrm{S}_{8}^{2+}$ both in the solid state and in solution ${ }^{76}$. It is believed to be the ion $\mathrm{S}_{4}^{+}$, present at low concentrations in equilibrium. 


\section{STRONGLY ACIDIC SOLVENT MEDIA}

The slow oxidation of sulphur with peroxodisulphuryl difluoride in sulphur dioxide at low temperature gives eventually a white product, $\mathrm{S}_{4}\left(\mathrm{SO}_{3} \mathrm{~F}\right)_{2}{ }^{78}$. On the basis of similarities between its Raman spectrum (solid state) and ultra-violet spectrum (in $\mathrm{SbF}_{5}-\mathrm{HSO}_{3} \mathrm{~F}$ solution) and those of $\mathrm{Se}_{4}^{2+}$, the solid is believed to contain the square-planar $\mathrm{S}_{4}^{2+}$ ion ${ }^{75}$. The compound $\mathrm{S}_{4}\left(\mathrm{SbF}_{6}\right)_{2}$ has also been obtained ${ }^{75,78}$.

The effect of solvent basicity on the stability of the cations of a given element is well illustrated by the behaviour of sulphur in sulphuric acid and oleums ${ }^{76}$. On prolonged heating at $75^{\circ} \mathrm{C}$ in $95-100 \%$ sulphuric acid, sulphur dissolves in the form of $\mathrm{S}_{8}$ molecules. In $5 \%$ oleum, oxidation to $\mathrm{S}_{16}^{2+}$ occurs. In 5-15\% oleum $\mathrm{S}_{8}^{2+}$ is formed, and above $15 \% \mathrm{SO}_{3}, \mathrm{~S}_{4}^{2+}$ is the predominant species. Thus, as expected, the ions with the higher charge per atom are stable in the more acidic media. In oleum containing less than $15 \% \mathrm{SO}_{3}, \mathrm{~S}_{8}^{2+}$ tends to disproportionate to $\mathrm{S}_{16}^{2+}$ and $\mathrm{SO}_{2}$, and in oleum containing less than $30 \%$ $\mathrm{SO}_{3}, \mathrm{~S}_{4}^{2+}$ is partly disproportionated to $\mathrm{S}_{8}^{2+}$ and $\mathrm{SO}_{2}$. The higher oxidation state, $\mathrm{S}(\mathrm{IV})$, is stabilized by coordination of $\mathrm{O}^{2-}$, which is derived from the solvent anion according to some such scheme as:

$$
2 \mathrm{HS}_{2} \mathrm{O}_{7}^{-}=\mathrm{H}_{2} \mathrm{~S}_{2} \mathrm{O}_{7}+2 \mathrm{SO}_{3}+\left[\mathrm{O}^{2-}\right]
$$

so that, for example, the disproportionation of $\mathrm{S}_{4}^{2+}$ may be written as:

$$
15 \mathrm{~S}_{4}^{2+}+16 \mathrm{HS}_{2} \mathrm{O}_{7}^{-} \rightleftharpoons 7 \mathrm{~S}_{8}^{2+}+4 \mathrm{SO}_{2}+8 \mathrm{H}_{2} \mathrm{~S}_{2} \mathrm{O}_{7}+16 \mathrm{SO}_{3}
$$

The tendency of a given cation to disproportionate in a sufficiently basic medium to a lower and a higher oxidation state, the latter being stabilized by coordination, has already been illustrated for $\mathrm{Br}_{2}^{+}$(equation 12) $\mathrm{Br}_{3}^{+}$ (equation 52) and $\mathrm{I}_{2}^{+}$(equation 48) in fluorosulphuric acid.

As highly electrophilic species, the polyatomic Group VI cations and their compounds are of great interest as potential synthetic reagents. Paige and Passmore ${ }^{79}$ have recently studied the reaction of perfluoroethylene with the compound $\mathrm{S}_{8}\left(\mathrm{AsF}_{6}\right)_{2}$ :

$$
\mathrm{C}_{2} \mathrm{~F}_{4}+\mathrm{S}_{8}\left(\mathrm{AsF}_{6}\right)_{2}^{\text {room temp. }}\left(\mathrm{C}_{2} \mathrm{~F}_{5}\right)_{2} \mathrm{~S}_{x} \quad(x=2-6)
$$

The corresponding selenium compound reacts similarly ${ }^{80}$ :

$$
\mathrm{C}_{2} \mathrm{~F}_{4}+\mathrm{Se}_{8}\left(\mathrm{AsF}_{6}\right)_{2} \stackrel{\text { room temp. }}{\longrightarrow}\left(\mathrm{C}_{2} \mathrm{~F}_{5}\right)_{2} \mathrm{Se}_{x} \quad(x=2,3)
$$

The compound $\mathrm{Se}_{8}\left(\mathrm{Sb}_{2} \mathrm{~F}_{11}\right)_{2}$, containing the less basic anion, reacts similarly at $100^{\circ}$. In solution in liquid sulphur dioxide, the reaction with $\mathrm{Se}_{8}\left(\mathrm{AsF}_{6}\right)_{2}$ gave, in addition to $\left(\mathrm{C}_{2} \mathrm{~F}_{5}\right)_{2} \mathrm{Se}_{2}$, the novel compound, perfluoroethyldiselenylperfluoroacetyl fluoride, $\mathrm{C}_{2} \mathrm{~F}_{5} \mathrm{Se}_{2} \mathrm{CF}_{2} \mathrm{COF}$. The reaction of perfluoropropylene with selenium and antimony pentafluoride in sulphur dioxide gave a number of selenium-containing products ${ }^{81}$ :

$$
\begin{aligned}
\mathrm{CF}_{3} \mathrm{CFCF}_{2}+\mathrm{Se}+\mathrm{SbF}_{5} \stackrel{\mathrm{SO}_{2}, 120^{\circ}}{\longrightarrow} & \left(\mathrm{CF}_{3}\right)_{2} \mathrm{CFSeCF}\left(\mathrm{CF}_{3}\right)_{2} \\
& \left(\mathrm{CF}_{3}\right)_{2} \mathrm{CFSe}_{2} \mathrm{CF}\left(\mathrm{CF}_{3}\right)_{2} \\
& \left(\mathrm{CF}_{3}\right)_{2} \overbrace{\mathrm{Se}^{\prime}}^{+} \mathrm{Ce}^{-} \mathrm{CF}_{3})_{2}
\end{aligned}
$$




\section{JOHN B. SENIOR}

The $\mathrm{Se}_{4}^{2+}$ cation was postulated as an intermediate in this reaction. It is clear that the reactions of these novel electrophiles have scarcely begun to be explored, and many further interesting developments are to be expected.

\section{REFERENCES}

1 D. Schioeberg and G. Zundel, J. Chem. Soc. Faraday 2, 69, 771 (1973).

2 B. E. Conway in Modern Aspects of Electrochemistry, No. 3, pp 43-148; B. E. Conway and J. O'M. Bockris, Eds. Butterworth; London (1964).

3 (a) N. N. Greenwood and A. Thompson, J. Chem. Soc. 3474 (1959).

(b) R. H. Flowers, R. J. Gillespie, E. A. Robinson and C. Solomons, J. Chem. Soc. 4327 (1960).

${ }^{4}$ P. A. H. Wyatt, Trans. Faraday Soc. 57, 773 (1961).

5 M. M. Nour and S. Wasif, J. Chem. Soc. A, 3024 (1968).

${ }^{6}$ N. N. Greenwood and A. Thompson, J. Chem. Soc. 3485 (1959).

7 R. S. Drago and K. F. Purcell in Progress in Inorganic Chemistry, Vol. 6, pp 271-322.

F. A. Cotton, Ed. Wiley-Interscience: New York (1964).

8 V. Gutmann, Coordination Chemistry in Non-Aqueous Solutions. Springer: New York (1968).

9 U. Mayer and V. Gutmann, Struc. and Bond. 12, 113 (1972).

10 S. J. Bass and R. J. Gillespie, J. Chem. Soc. 814 (1960).

11 R. H. Flowers, R. J. Gillespie and E. A. Robinson, J. Chem. Soc. 845 (1960).

12 J. Barr, R. J. Gillespie and R. C. Thompson, Inorg.Chem. 3, 1149 (1964).

13 E. A. Robinson and J. Ciruna, Canad. J. Chem. 46, 1719 (1968).

${ }^{14}$ R. J. Gillespie and M. J. Morton, Inorg. Chem. 11, 586 (1972).

15 R. J. Gillespie and R. F. M. White, Canad. J. Chem. 38, 1371 (1960).

16 T. Birchall and R. J. Gillespie, Canad. J. Chem. 42, 502 (1964).

17 J. Shamir and A. Netzer, Canad. J. Chem. 51, 2676 (1973).

18 Z. I. Grigorovich, Yu. I. Malov and V. Ya. Rosolovskii, Izvest. Akad. Nauk SSSR, Ser. Khim. 265 (1972).

19 R. J. Gillespie, Endeavour, 32, 3 (1973).

20 R. J. Gillespie and K. C. Malhotra, J. Chem. Soc. A., 1994 (1967).

${ }^{21}$ R. H. Flowers, R. J. Gillespie and J. V. Oubridge, J. Chem. Soc. 1925 (1956).

22 J. Barr, R. J. Gillespie and E. A. Robinson, Canad. J. Chem. 39, 1266 (1961).

${ }^{23}$ R. J. Gillespie and E. A. Robinson, in Non-Aqueous Solvent Systems, p 170. T. C. Waddington, Ed. Academic Press: London (1965).

24 R. J. Gillespie and E. A. Robinson, in Non-Aqueous Solvent Systems, p 172. T. C. Waddington, Ed. Academic Press: London (1965).

25 D. G. Russell and J. B. Senior, Canad. J. Chem. in press.

26 R. J. Gillespie and E. A. Robinson, Canad. J. Chem. 40, 675 (1962).

27 R. C. Thompson, J. Barr, R. J. Gillespie, J. B. Milne and R. A. Rothenbury, Inorg. Chem. 4, 1641 (1965).

${ }^{28}$ G. A. Olah, A. M. White and D. H. O'Brien, Chem. Rev. 70, 561 (1970).

29 R. J. Gillespie, K. Ouchi and G. P. Pez, Inorg. Chem. 8, 63 (1969).

${ }^{30}$ R. J. Gillespie, personal communication.

31 M. F. A. Dove and A. F. Clifford in Chemistry in Nonaqueous Ionizing Solvents Vol. II, Part I, p 174. G. Jander, H. Spandau and C. C. Addison, Eds. Pergamon: London (1971).

32 R. J. Gillespie and K. C. Moss, J. Chem. Soc. A, 1170 (1966).

33 C. H. Rochester, Acidity Functions. Academic Press: London (1970).

34 J. C. D. Brand, J. Chem. Soc. 997 (1950);

J. C. D. Brand, W. C. Horning and M. B. Thornby, J. Chem. Soc. 1374 (1952).

35 V. A. Palm, Proc. Acad. Sci. USSR, Sect. Chem. 108, 249 (1956).

${ }^{36}$ R. J. Gillespie, T. E. Peel and E. A. Robinson, J. Amer. Chem. Soc. 93, 5083 (1971).

37 R. J. Gillespie and T. E. Peel, J. Amer. Chem. Soc. 95, 5173 (1973).

38 Reference 23, p 161.

39 D. M. Brouwer and J. A. Van Doorn, Rec. Trav. Chim. Pays-Bas, 91,895 (1972).

40 R. J. Gillespie and M. J. Morton, Quart. Rev. 25, 553 (1971).

41 R. A. Garrett, R. J. Gillespie and J. B. Senior, Inorg. Chem. 4, 563 (1965).

42 J. Arotsky, H. C. Mishra and M. C. R. Symons, J. Chem. Soc. 2582 (1962). 


\section{STRONGLY ACIDIC SOLVENT MEDIA}

43 R. J. Gillespie and J. B. Milne, Inorg. Chem. 5, 1236 (1966).

44 D. J. Merryman, P. A. Edwards, J. D. Corbett and R. E. McCarley, Chem. Commun. 779 (1972).

45 J. B. Senior and J. L. Grover, Canad. J. Chem. 49, 2688 (1971).

46 C. G. Vonk and E. H. Wiebenga, Acta Cryst. 12, 859 (1959).

47 R. J. Gillespie and K. C. Malhotra, Inorg. Chem. 8, 1751 (1969).

48 J. Shamir and M. Lustig, Inorg. Chem. 12, 1108 (1973).

49 D. J. Merryman and J. D. Corbett, Inorg. Chem. 13, 1258 (1974).

50 W. W. Wilson and F. Aubke, Inorg. Chem. 13, 326 (1974).

51 J. Arotsky and M. C. R. Symons, Quart. Rev. 16, 282 (1960).

52 R. J. Gillespie and J. B. Milne, Inorg. Chem. 5, 1577 (1966).

53 R. D. W. Kemmitt, M. Murray, V. M. McRae, R. D. Peacock, M. C. R. Symons and T. A. O'Donnell, J. Chem. Soc. A, 862 (1968).

54 R. J. Gillespie, J. B. Milne and M. J. Morton, Inorg. Chem. 7, 2221 (1968).

55 O. Glemser and A. Smale, Angew. Chem. Internat. Ed. 8, 517 (1969).

56 A. J. Edwards, G. R. Jones and R. J. C. Sills, Chem. Commun. 1527 (1968).

${ }^{57}$ R. J. Gillespie and M. J. Morton, Chem. Commun. 1565 (1968);

R. J. Gillespie and M. J. Morton Inorg. Chem. 11, 591 (1972).

58 G. A. Olah and M. B. Comisarow, J. Amer: Chem. Soc. 90, 5033 (1968); 91, 2172 (1969).

59 R. J. Gillespie and M. J. Morton, Inorg. Chem. 9, 811 (1970).

60 R. J. Gillespie and J. Passmore, Accts Chem. Res. 4, 413 (1971).

61 J. Barr, R. J. Gillespie, R. Kapoor and G. P. Pez, J. Amer. Chem. Soc. 90, 6855 (1968).

62 N. J. Bjerrum and G. P. Smith, J. Amer. Chem. Soc. 90, 4472 (1968);

N. J. Bjerrum, Inorg. Chem. 9, 1965(1970).

63 J. Barr, R. J. Gillespie, G. P. Pez, P. K. Ummat and O. C. Vaidya, J. Amer. Chem. Soc. 92, $1081(1970)$.

64 J. Barr, R. J. Gillespie, G. P. Pez, P. K. Ummat and O. C. Vaidya, Inorg. Chem. 10, 362 (1971).

65 R. C. Paul, C. L. Arora, J. K. Puri, R. N. Virmani and K. C. Malhotra, J. Chem. Soc. Dalton, 781 (1972).

66 T. W. Couch, D. A. Lokken and J. D. Corbett, Inorg. Chem. 11, 357 (1972).

67 P. J. Stephens, Chem. Commun. 1496 (1969).

68 N. J. Bjerrum, Inorg. Chem. 11, 2648 (1972).

69 D. J. Prince, J. D. Corbett and B. Garbisch, Inorg. Chem. 9, 2731 (1970).

70 J. Barr, R. J. Gillespie, R. Kapoor and K. C. Malhotra, Canad. J. Chem. 46, 149 (1968).

71 J. Barr, D. B. Crump, R. J. Gillespie, R. Kapoor and P. K. Ummat, Canad. J. Chem. 46, 3607 (1968).

72 R. J. Gillespie and P. K. Ummat, Canad. J. Chem. 48, 1240 (1970).

${ }^{73}$ R. K. McMullen, D. J. Prince and J. D. Corbett, Chem. Commun. 1438 (1969).

74 I. D. Brown, D. B. Crump and R. J. Gillespie, Inorg. Chem. 10, 2319 (1971).

75 R. J. Gillespie, J. Passmore, P. K. Ummat and O. C. Vaidya, Inorg. Chem. 10, 1327 (1971).

76 R. J. Gillespie and P. K. Ummat, Inorg. Chem. 11, 1674 (1972).

77 C. Davies, R. J. Gillespie, J. J. Park and J. Passmore, Inorg. Chem. 10, 2781 (1971).

78 J. Barr, R. J. Gillespie and P. K. Jmmat, Chem. Commun. 264 (1970).

79 H. L. Paige and J. Passmore, Inorg. Chem. 12, 593 (1973).

80 C. D. Desjardins and J: Passmore, J. Chem. Soc. Dalton, 2314 (1973).

81 Yu. L. Kopaevich, G. G. Belen'kii, E. I. Mysov, L. S. German and I. L. Knunyants, $Z h$. Vsesoyuz Khim. obschim. D. I. Mendeleeva, 17, 266 (1972). 